\title{
EL EMPLEO DEL RONZAL CABALLAR EN EL NORTE DEL EBRO DURANTE LA EDAD DEL HIERRO Y LA ÉPOCA IBÉRICA
}

BY

\author{
IGNASI GARCÉS ESTALLO*
}

\begin{abstract}
RESUMEN - ABSTRACT
La atenta observación de una antigua fotografía de un caballo sacrificado en la necrópolis de la Edad del Hierro de La Pedrera (Térmens, Lleida) evidencia el uso del aro para ronzal en el valle del Segre durante ese momento. A su vez, es el punto de partida de una breve investigación sobre el empleo de ronzales para équidos en los entornos catalán y aragonés. Se reconocen otros dos posibles casos en bronce y se detecta un paralelo iconográfico que, aunque conocido, había pasado desapercibido, y que confirma la pervivencia de tal práctica hasta comienzos de la dominación romana. En los ejemplares metálicos conservados el sistema de cierre se distancia de las soluciones adoptadas en el área levantina, para acercarse a las tradiciones centroeuropeas, en sintonía con otros aspectos culturales propios del norte del Ebro, como son los elementos de monta del caballo y, en general, del armamento.

L'observation attentive d'une photographie ancienne d'un cheval sacrifié dans la nécropole de l'Âge du Fer de La Pedrera (Térmens, Lleida) évidence l'usage de l'anneau pour licou dans la vallé du Segre durant ce moment. À son tour, c'est le point de départ d'une brève investigation sur l'emploi de licous pour équidés dans les environnements catalan et aragonais. D'autres deux cas possibles se reconnaissent dans bronze et on détecte un parallèle iconographique que, bien qu'une connaissance, eût passé inaperçu, et qui confirme la survivance de telle pratique jusqu'aux commencements de la domination romaine. Dans les exemplaires métalliques conservés le système de fermeture se sépare des solutions adoptées dans le domaine du Levant, pour s'approcher des traditions de l'Europe centrale, dans un réglage avec d'autres aspects culturels propres du nord de l'Ebre, comme ce sont les éléments de monte du cheval et, en général, de l'armement.
\end{abstract}

\section{PALABRAS CLAVE - KeYWORDS}

Caballo. Ronzal. Edad del Hierro. Iberos. Romanización. Aristocracia ecuestre. Valle del Ebro.

Cheval. Licou. Âge du Fer. Ibères. Romanisation. Aristocratie équestre. Val de l’Ébre.

\section{INTRODUCCIÓN}

En los últimos años diversos estudios han demostrado el empleo de aros metálicos y ronzales para la conducción o sujeción de caballos durante la protohistoria peninsular. Los métodos seguidos en esos trabajos han consistido en la recuperación de antiguos datos de excavaciones, el análisis de objetos guardados en museos y la comparación iconográfica. Entre esas

\footnotetext{
* Departamento de Prehistoria, Historia Antigua y Arqueología, Universidad de Barcelona, c/ Montalegre
} 6-8, 08001 Barcelona. 
aportaciones cabe destacar la evidencia de tal práctica en el entorno ibérico valenciano (Mesado, 2003), la correlación con ejemplos centroeuropeos prerromanos (Quesada, 2003: 14-16; 2005: 123-125), la indagación de los orígenes prehistóricos y la extensión a la región murciana durante la época ibérica de tan peculiar forma de conducir los équidos (Lucas, 2004). Mediante el presente trabajo, y con idéntica metodología, proponemos la ampliación de dicha práctica al norte del Ebro, donde hemos identificado los primeros casos, todavía poco numerosos, aunque ya abarcan una extensa zona y una cronología dilatada.

\section{NUEVOS DATOS EN EL NORTE DEL EBRO}

\section{ARO DE BRONCE EN LA NECRÓPOLIS DE LA PEDRERA (TÉRMENS, LLEIDA)}

El yacimiento de La Pedrera se ubica en la comarca de la Noguera, en tierras llanas próximas al río Segre al norte de la ciudad de Lleida. Las circunstancias que rodearon el descubrimiento de su necrópolis fueron poco afortunadas, ya en los años 30 del siglo XX se habían producido algunos hallazgos, posteriormente perdidos (Ripoll, 1959: 279), pero los materiales y datos científicos hoy conservados proceden de unos desmontes que acontecieron en 1958. En esa ocasión aparecieron objetos sin control alguno, más tarde representantes del Instituto de Estudios Ilerdenses realizaron algunas excavaciones, localizando varios caballos

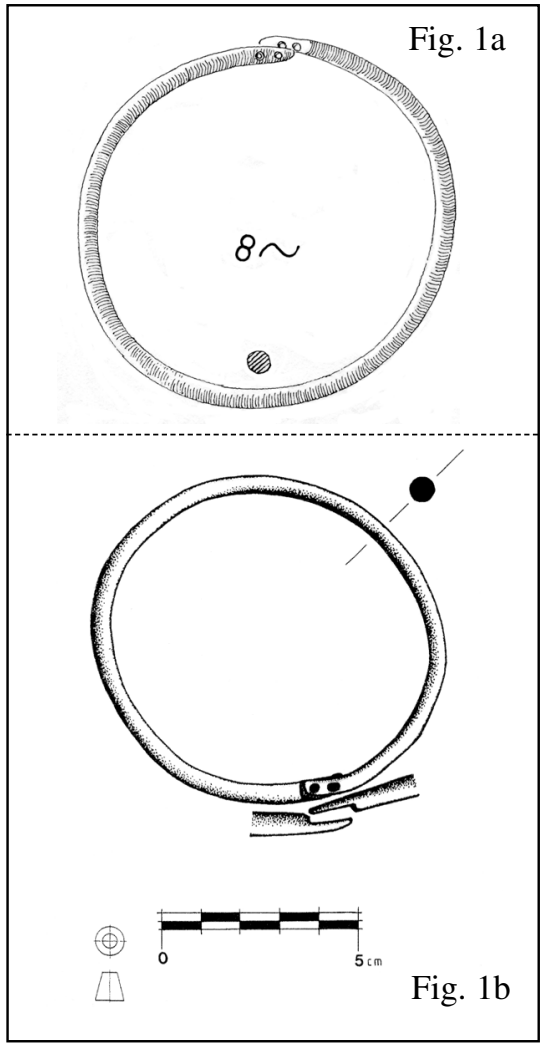

Fig. 1. Aro de ronzal caballar de La Pedrera. A) según W. Schüle, 1969: fig. 182.8; B) según M. Plens, 2002: 179, dibujo de A. Llussà. sacrificados, uno de los cuales portaba el objeto que aquí nos ocupa. Dichos trabajos no legaron una documentación adecuada aunque, como mínimo, generaron diversas fotografías. Poco después la Universidad de Barcelona desplazó un supervisor que documentó otro sector. En síntesis, no se dispone todavía de una monografía exhaustiva del material procedente de dicha necrópolis, pese a algunos intentos (Plens, 1986) y a la publicación de algunas notas y selecciones de objetos (Rafel, 2002: 255-256).

La argolla para ronzal detectada es de forma casi circular, de $8 \mathrm{~cm}$ de diámetro, abierta en los extremos acabados en lengüetas que se adelgazan y superponen encajando entre sí, a la vez que contienen dos agujeros perpendiculares que también encajan, por los que pasarían unos vastaguillos con el fin de asegurar un correcto cierre; la sección es circular (fig. 1.a-b). Actualmente se conserva en la Sala de Arqueología del Instituto de Estudios Ilerdenses, núm. de inventario: L-1259. Su justificación como elemento para el arrastre del caballo puede demostrarse mediante una fotografía de Luis Díez-Coronel (fig. 2), representante del Instituto de Estudios Ilerdenses, realizada durante la exhumación. En la imagen la broncínea argolla aparece in situ, rodeando el maxilar inferior de un cráneo de caballo hincado; inclusive, puede apreciarse con todo detalle el cierre de la pieza, pues éste aparece en primer plano. Dicha fotografía ya había sido publicada en diversas ocasiones para ilustrar el sacrificio (Maya, 1986: 43; Rafel, 2002: 255), pero no 


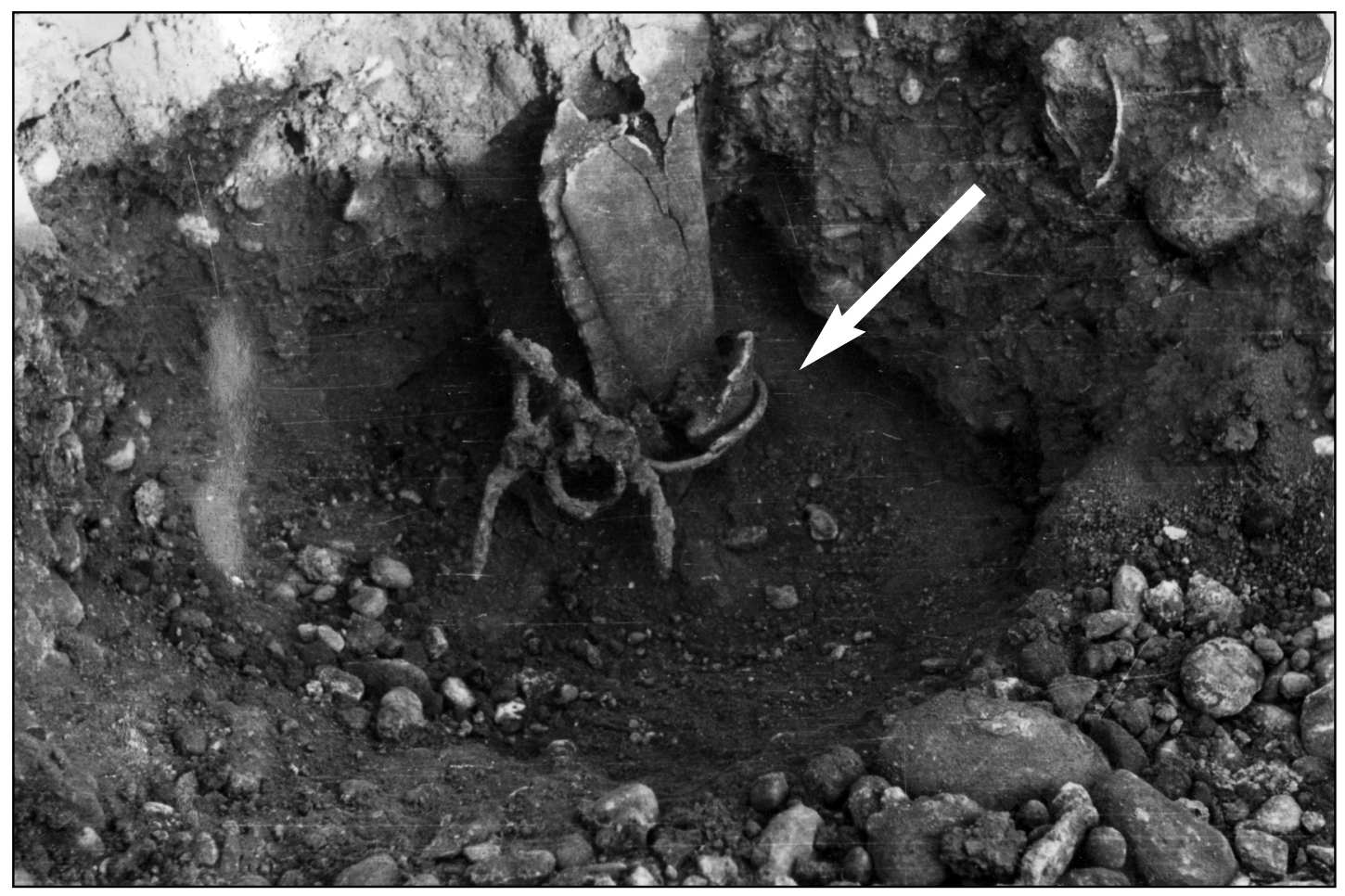

Fig. 2. Restos in situ del cráneo de un équido con bocado de hierro y aro de bronce (señalado por una flecha) de la figura anterior. La Pedrera (Térmens, Lleida), Fotografía: Servei d'Audiovisuals de l'IEI, Arxiu Fotogràfic.

se había interpretado en el sentido que ahora proponemos. Por su parte, el aro para ronzal había sido publicado en anteriores ocasiones por autores que desconocían tal fotografía (Schüle, 1969: fig. 182.8; Plens, 1986: 112 y fig. 63.4; 2002: 179). Igual que sucedía en otros lugares la argolla, una vez descontextualizada, había sido considerada erróneamente un brazalete de gran tamaño y tipología poco común, constituyendo el único ejemplar del tipo IV de brazaletes de ese yacimiento en la clasificación de Mercè Plens, pese a que la autora no podía señalar paralelos en otros lugares.

Debido al hecho de desconocerse una correlación estratigráfica para el depósito del caballo sacrificado que nos ocupa, la datación del aro caballar debe establecerse mediante su asociación con un freno de hierro que aparece en la misma imagen y a la fecha relativa que a éste se adjudique. Dicho freno pertenece al tipo Szentes-Vekerzúg (Schüle, 1969: 46 y 126), y su datación quedaría establecida entre finales del siglo VII y todo el siglo VI a.C. (en último lugar Garcés, 2002: 200). Tal cronología convierte el aro de ronzal de La Pedrera en el más antiguo de su especie por ahora conocido, culturalmente situado entre finales de la Edad del Hierro y comienzos de la cultura ibérica en la zona, pues esta se produce a mediados del siglo VI a.C. Dentro de la dinámica del yacimiento de La Pedrea corresponde a un momento intermedio, puesto que esa necrópolis ya era activa en los siglos XI-IX a.C., se desconoce la fase intermedia, pero retoma una gran actividad en los siglos VI-V a.C., y residualmente en el IV a.C. (Rafel, 2002: 255).

El sistema de cierre que muestra el aro caballar de La Pedrera, basado en el adelgazamiento y superposición de los extremos unidos mediante dos agujeros transversales, se reproduce exactamente en el aro de hierro de la inhumación caballar de Sopron-Krautacker (noroeste de Hungría) (fig. 3), bastante más moderno, pues el entierro puede ser fechado a mediados o durante el segundo tercio del siglo II a.C. (Jerem, 1998: 331; Quesada, 2003: 14-15). 


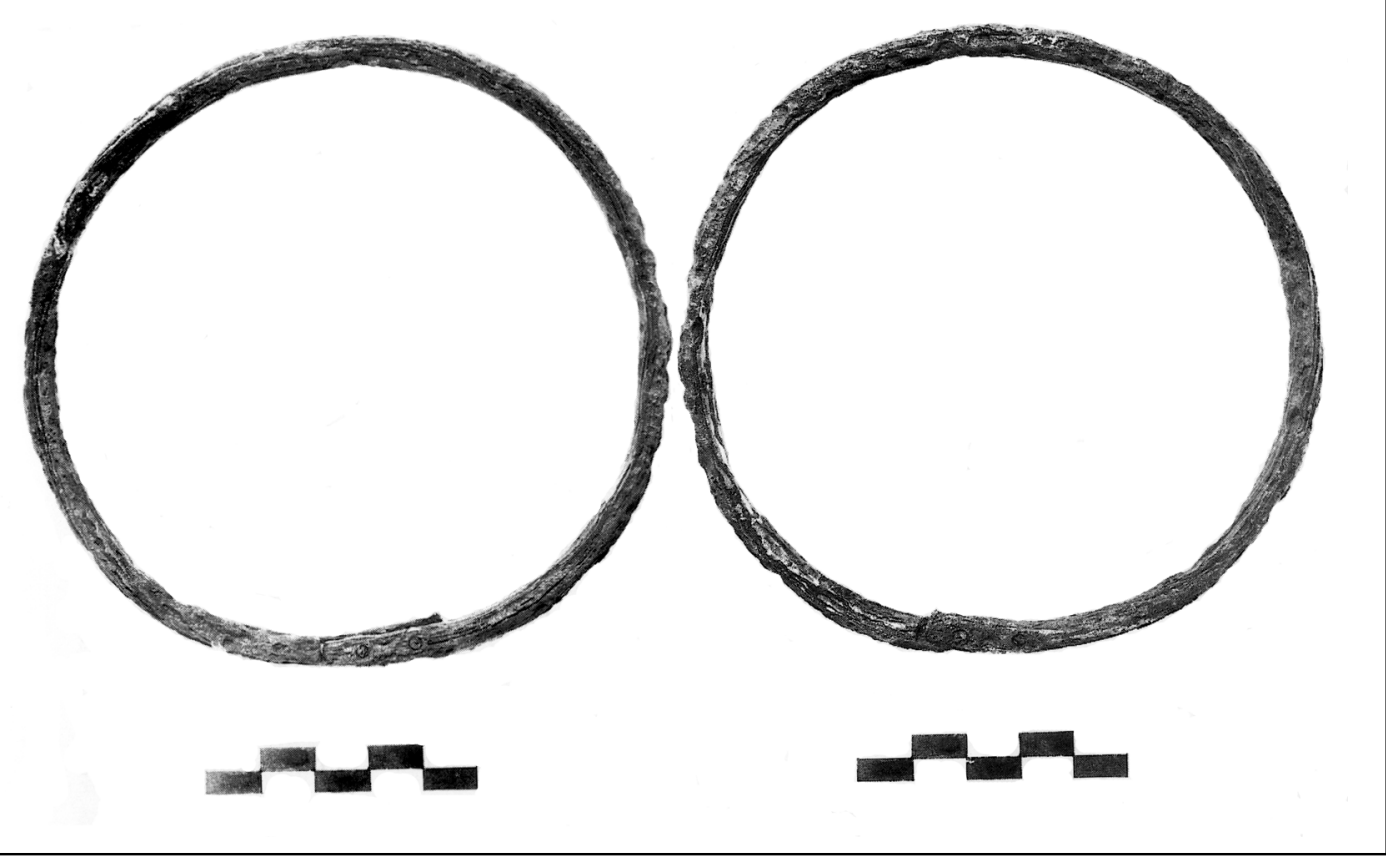

Fig. 3. Aro de ronzal caballar férreo de Sopron-Krautacker (noroeste de Hungría), según Jerem 1998: 327.

Ya hemos indicado la coexistencia en el caballo de La Pedrera de un freno de hierro y de un aro de bronce para ronzal, analicemos ahora el hecho desde otra perspectiva: la singularidad de dicha asociación. En los otros ejemplos de caballos sacrificados que tenemos constancia la argolla aparece sola, indicando que esos caballos no fueron llevados al sacrificio montados, sino guiados, como bien ha señalado Fernando Quesada (Quesada, 2003: 14). En el ejemplar de La Pedrera no resulta tan fácil aseverarlo, aunque creemos más verosímil la posibilidad que también aquí fuese guiado, con la particularidad que además debió serlo ricamente guarnecido. En cualquier caso, la asociación de bocado férreo de camas curvas y argolla de bronce se reproduciría, de alguna forma, en el ajuar de la tumba principesca n. 200 de la necrópolis de El Cigarralejo (Mula, Murcia), que también contenía una pareja humana de distinto sexo y al parecer un carro (Lucas, 2004: 104). Frenos y bocados reforzarían el sentido elitista de algunos enterramientos destacados.

Otro elemento de reflexión que aporta el "nuevo" caso de La Pedrera es entorno al concepto narigón, expresivo vocablo rural que designa una cuerda o argolla utilizada para el arrastre de bueyes, que la malograda doctora $\mathrm{M}^{\mathrm{a}}$ Rosario Lucas hizo extensivo a los caballos en su trabajo póstumo (Lucas, 2003: 100, aceptado por Quesada, 2005: 123-125). A pesar del interés que suscita dicha propuesta, provisionalmente nos abstenemos de utilizar tal término, dado que no nos consta ningún ejemplo equino bien documentado en el que las argollas apareciesen fuera del maxilar superior, como correspondería en el caso de haber atravesado la ternilla de los ollares. Las fotografías de los otros caballos sacrificados que conocemos -Sopron en Hungría (Jerem, 1998: fig. 5), Altino-Le Brustolade en la región véneta (Jerem, 1998: fig. 7) y, con más problemas de documentación, La Regenta-Burriana en Castellón (Mesado, 2003: lám. I; Sarrión, 2003: fig. 10), coinciden con el ejemplo que aquí nos ocupa: en todos esos casos la argolla siempre rodea el maxilar inferior, posición lógica si aquella atravesaba los belfos del animal. El análisis arqueozológico del caballo de Sopron parece reforzar este punto, pues tal 
artilugio, aplicado posiblemente desde la juventud del animal, le causó la ruptura prematura de los colmillos y la distorsión de parte del diastema de la mandíbula (Jerem, 1998: 326). Por lo que concierne a los ejemplos iconográficos peninsulares conservados no resulta fácil pronunciarse sobre el lugar exacto en que se alojaba la argolla, aún así, el presunto narigón parece surgir del morro, dependiendo del espacio disponible y de la habilidad del artista de turno, en unos casos de su extremo superior, en otros del centro, sin faltar ejemplos en que sujeta claramente el belfo inferior, descartando así la ubicación en los ollares. Es por ello que por ahora preferimos los términos neutros de aro o argolla para referirnos al elemento metálico. El cabo o cuerda que sujetaría el extremo metálico se denominaría jáquima, vocablo derivado del árabe. Con el nombre de ronzal (del árabe rasán, su equivalente latino sería capistrum, cabestro) se designa, indistintamente a todo el conjunto o simplemente a la cuerda atada a la cabeza de la caballería que permite conducir o sujetar el animal, según convenga. Estas razonables dudas sobre el empleo del narigón caballar no implican volver al termino bocado, como muy bien señaló $\mathrm{M}^{\mathrm{a}} \mathrm{R}$. Lucas; por más que los aros metálicos, a nuestro entender, se alojaban en la boca, no son elementos para el gobierno montado del caballo.

Finalmente, indicamos que resulta curiosa la posición, nada natural, de los maxilares del équido de La Pedrera que se observan en la fotografía aludida, puesto que descansan de forma vertical. Esa rareza puede indicar que tal vez estamos delante del depósito de una cabeza equina separada previamente de su cuerpo, dentro de un ritual más complejo de lo que a primera vista viene considerándose, aunque no es este el lugar para extendernos sobre esa problemática, que reservamos para un futuro trabajo. Apuntamos que no es nueva la observación de caballos decapitados en yacimientos protohistóricos peninsulares, por ejemplo en Cancho Roano (Sánchez-Moreno, 2005: 246).

\section{ARO DE BRONCE EN EL TURÓ DEL VENT (LLINARS DEL VALLÈS, BARCELONA)}

Mientras realizábamos este trabajo, gracias a las indicaciones del Sr. Ramón Álvarez, tuvimos noticia de un nuevo fragmento de aro en bronce, inédito, que él personalmente había dibujado en el Museo Municipal de Llinars del Vallès, y que le recordaba un elemento de gobierno caballar. El objeto en cuestión procede del poblado layetano del Turó del Vent, sin ningún contexto, y lo reproducimos merced a la generosidad de dicho investigador (fig. 4). Se trata de un fragmento de argolla, quizás reutilizada pues un extremo aparece suavizado, de la que no puede determinarse con exactitud su diámetro, pero de la que llama poderosamente la atención el sistema de cierre seguido, pues su extremo se adelgaza al tiempo que se ensancha, para encajar, mediante dos agujeros -uno visible y otro deducible en la ruptura- con el extremo contrario, en parte conservado, al igual que uno de los remaches que lo sustenta; la sección también es circular. El tipo de cierre desaconseja la posibilidad de un brazalete o torques, para emparentarse con la argo-

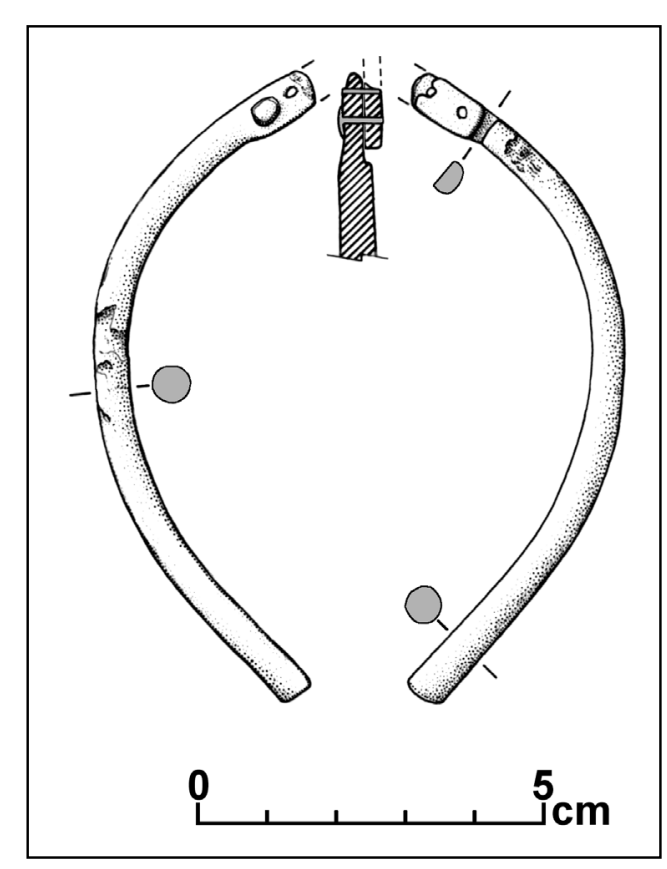

Fig. 4. Fragmento de aro de ronzal del Turó del Vent (Llinars del Vallès, Barcelona), dibujo de R. Álvarez. 
lla de La Pedrera, pero nada nos garantiza su función como aro para la conducción de équidos y abre un abanico de posibilidades. A falta de un contexto preciso para el objeto indicado, debemos hacer extensiva la fechación general de todo el yacimiento, que ha podido ser determinada entre mediados o quizá principios del siglo IV y principios del siglo II a.C. (López et al., 1982: 107).

\section{POSIBLE ARO DE BRONCE EN EL TOSSAL DE LES TENALLES (SIDAMON, LLEIDA)}

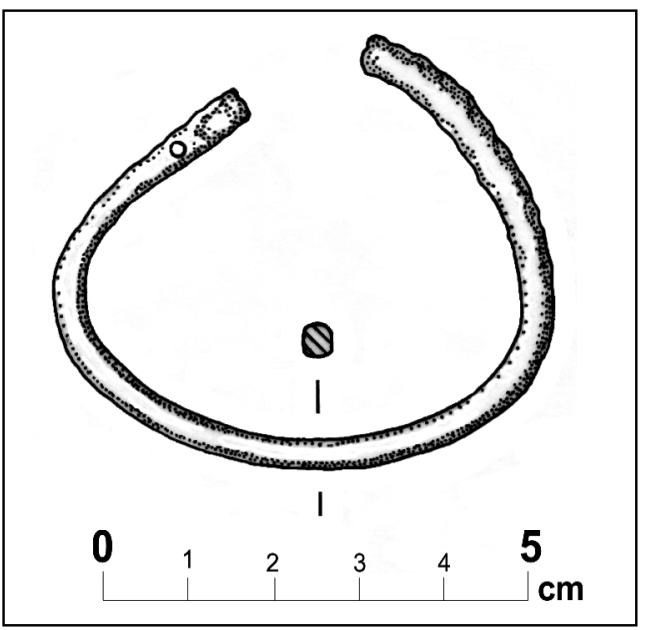

Fig. 5. Posible aro de ronzal del Tossal de les Tenalles (Sidamon, Lleida), según Garcés et al. 1993: 279.

Al este de Lleida, en la comarca del Pla d'Urgell es bien conocido el poblado ibérico del Tossal de les Tenalles, debido a la pionera excavación del Institut d'Estudis Catalans en el año 1915. En 1982-1988 se reemprendieron nuevos trabajos, que sacaron a la luz una cisterna colmatada en un momento cercano al conocimiento local de la cerámica torneada, pero todavía anterior a ésta y que muy bien podría ser fijado en la primera mitad del siglo VI a.C. (Garcés et al., 1993). En concreto, en la unidad estratigráfica 80 , apareció un aro de bronce de forma oval, con los extremos abiertos, uno perdido o reutilizado y el otro presentando un remache plano con un agujero perpendicular; las dimensiones son pequeñas: 5' 1 x 4' $4 \mathrm{~cm}$, y la sección del objeto es cuadrada (fig. 5) (Garcés et al., 1993: 269 y fig. 21, 8). Inicialmente lo consideramos un brazalete, citando como paralelo más próximo el objeto ya presentado de La Pedrera. Reconocida una nueva función para éste segundo, debe buscarse una nueva propuesta para el primero, pero como argolla caballar resulta delgada y pequeña, además de no poseer la habitual sección circular. Por ello no deben descartarse otras posibles funciones: la de narigón para algún animal doméstico más pequeño, o la de aro de sujeción de otro elemento metálico.

\section{REPRESENTACIÓN DE AROS Y JAQUIMAS EN EL RELIEVE N. 2 DE LA VISPESA (TAMARITE DE LITERA, HUESCA)}

La Vispesa es una estación ibérica emplazada en una pequeña altura sobre los llanos del término municipal de Tamarite de Litera que, debido a hallarse a tan sólo tres kilómetros del núcleo urbano de Binéfar, con frecuencia ha sido publicada como vinculada a esa última población. Hacia 1964, en la parte baja del montículo, se halló una gran piedra en forma de paralelepípedo con relieves, que medía aproximadamente 2 × 1 x $0,5 \mathrm{~m}$; pronto fue intencionadamente partida en trozos y estos utilizados como falcas de una canalización de riego. En 1968 se recuperaron algunas porciones que ingresaron en el Museo de Huesca. Los fragmentos resultantes formaron dos conjuntos, el relieve n. 1, el más conocido por su temática de cuerpos y manos amputadas (Beltrán, 1970; Marco, Baldellou, 1976), y el relieve n. 2, con temática de caballos (Beltrán, 1970). En 2001 realizamos un nuevo estudio y unos nuevos dibujos, encargados al Sr. Ramón Álvarez; en particular propusimos una nueva orientación del relieve n. 1, pero esos datos todavía permanecen básicamente inéditos (Garcés, en prensa). 
El relieve n. 2 está formado en la actualidad por tres fragmentos unidos. Fue realizado en arenisca y mide casi 0,8 m de alto, aunque solo conserva decoración en 0,69 m; el ancho es de $0,44 \mathrm{~m}$ y el grueso conservado es muy irregular, entre 0,10 y $0,18 \mathrm{~m}$ (fig. 6). No resulta fácil determinar si esta pieza corresponde a la parte posterior del monumento representado por el relieve n. 1, las informaciones orales del descubrimiento indican que el hallazgo original contenía un único bloque, y debe añadirse que el festón redondeado del extremo inferior del relieve 2 es muy parecido a su equivalente que enmarca los temas de la cara frontal del otro conjunto. En cualquier caso, la escena representada contenía previsiblemente cuatro caballos dispuestos por parejas afrontadas, de los cuales se conservan tres total o parcialmente. Los caballos carecen de mantas de montar y de cabezadas, pero reproducen con todo detalle los ronzales que los sujetan. Del belfo inferior de cada équido parte un pequeño aro, que continua en una jáquima que pasa por delante de un objeto vertical con punta en la base -tal vez un poste, estandarte o trofeo-, que contiene una inscripción ibérica incisa (MLH III, D.12.2., nuevos detalles en Garcés, prensa a), para unirse con la jáquima del équido contrario. Los équidos están resueltos siguiendo un patrón: las patas del fondo poseen menor relieve para dar sensación de profundidad, la cola aparece separada y se marcan las pezuñas mediante recortes; detalles como ojos y boca se resuelven con hendiduras, y la incisión ayuda a destacar las crines y los contornos de la cabeza. El ronzal se sujeta a los caballos mediante unos aros que surgen del comienzo de la barbada, indicando que se alojan en el belfo y no son narigones, siendo el ejemplar del ángulo inferior izquierdo el que permite asegurarlo mejor, pues en los otros dos casos la erosión superficial dificulta la observación, aunque creemos que era idéntica (fig. 6).

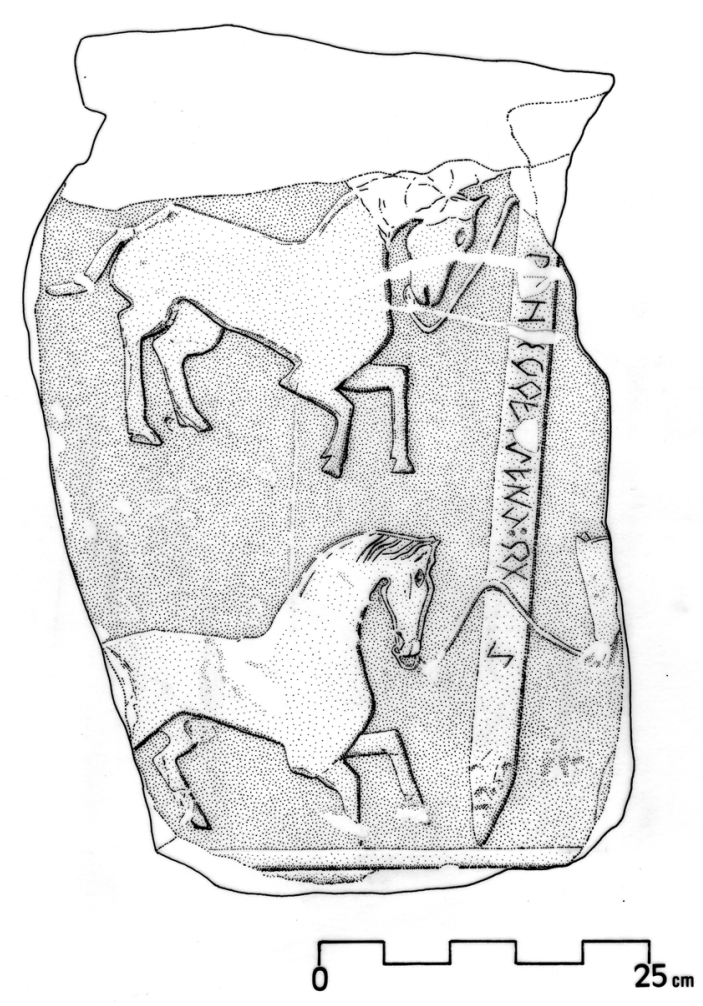

Fig. 6. Relieve n. 2 del Monumento de La Vispesa (Tamarite de Litera, Huesca), según Garcés, en prensa, dibujo de R. Álvarez. 


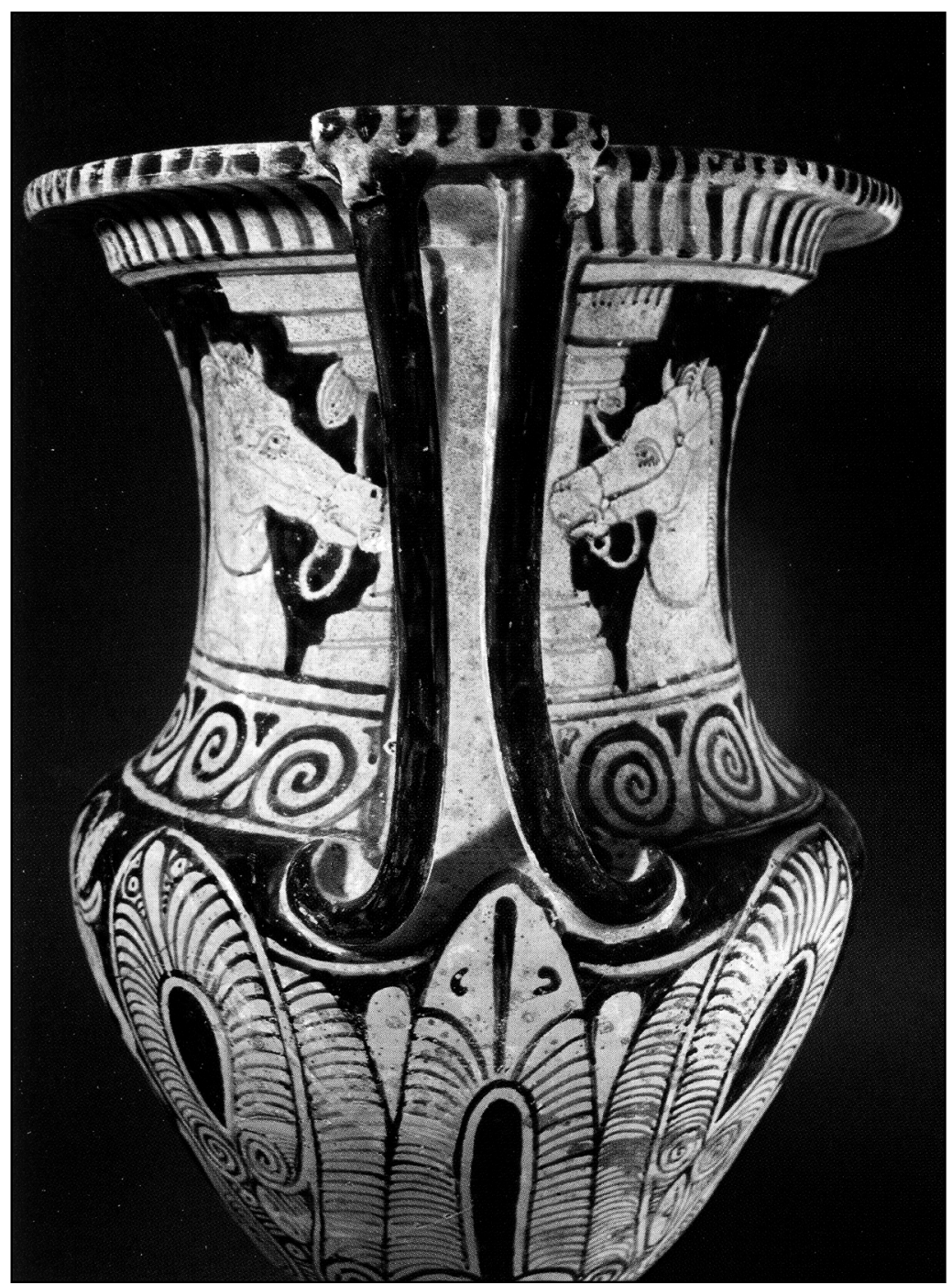

Fig. 7. Crátera etrusca del Pintor de Asciano, con caballos afrontados sujetados a una columna mediante ronzales y aros, según Martelli, 1987: fig. 179.4.

Si bien la temática de los caballos afrontados no es desconocida en el arte ibérico, p. e. en el relieve de Villaricos (Almería), suele presidir la escena un personaje bifronte, que en Villaricos aparece sentado sobre una silla (en último lugar VV.AA., 1998: n. 208), y que indica una fuerza sobrenatural dominadora o protectora de los caballos, muy diferente a la concepción escénica de La Vispesa. Una composición relativamente afín a la que aquí nos ocupa aparece en la crátera de columnas etrusca del Pintor de Asciano (310-300 a.C.), donde se puede observar el prótomo de cuatro caballos contrapuestos emblemáticamente dos a dos, con sus respectivos cabezales, flanqueando la representación frontal de dos rostros viriles (fig. 7). Las cabezas de esos caballos portan, como se ha dicho, cabezales, pero también una argolla en el belfo inferior, de la que pende un ronzal que pasa por detrás e indica que están sujetos a una columna que enmarca la escena (Martelli, 1987: fig. 179.4; Lucas, 2004: 107, fig. 6). La posición de los aros en el belfo inferior encuentra eco en La Vispesa. 
Respecto a la datación del relieve n. 2 en su día Antonio Beltrán ya reconoció el paralelo de algunas letras del relieve n. 1 con las monedas más antiguas de Tarraco, pero consideró esos detalles como arcaísmos, para concluir que el epígrafe y el monumento debían datarse en la segunda mitad del siglo I a.C. (Beltrán, 1970: 522). Francisco Marco y Vicente Baldellou, después de analizar el problema con detalle y traer a consideración los materiales hallados en superficie en el yacimiento, ampliaron el margen cronológico entre la segunda mitad del siglo II a.C. y el cambio de Era (Marco, Baldellou, 1976: 115). Nosotros consideramos que el juicio arcaizante puede ser subjetivo y no concluyente, que, comparaciones paleográficas en mano, ha habido también propuestas sugeridoras de principios o mediados del siglo II a.C. (Rodríguez Ramos, 1997: 16), y en último lugar pero no menos importante, que el monumento no procede estrictamente del poblado, por lo que nada garantiza una absoluta vinculación a éste y a sus restos descubiertos. Por todo lo anterior proponemos las primeras décadas del siglo II a.C. como datación más posible, como hemos defendido en otro lugar (Garcés, en prensa a). Desde un punto de vista histórico, la temática de exaltación guerrera visible en La Vispesa encaja mejor en un mundo indígena, todavía ajeno a los ideales urbanos que la romanización fue impulsando gradualmente.

\section{DISCUSIÓN Y CONCLUSIÓN}

\section{TIPOLOGIA}

Con los datos que hemos recuperando en el norte del Ebro es posible proponer una distinción de dos tipos de argollas para ronzal caballar en la Península, diferenciadas según el sistema de cierre empleado (fig. 8).

\section{Tipo 1}

Consta de dos extremos idénticos y rebajados con el fin de facilitar su encaje, que se sujetan mediante dos vastaguillos que atraviesan sendos agujeros perpendiculares. En este grupo cabe incluir, dentro de la Península, el ejemplar leridano de La Pedrera y el caso layetano del Turó del Vent. Su cronología arrancaría a finales del siglo VII o durante el VI a.C. y alcanzaría el siglo II a.C. Quizás pueda incluirse en este grupo el objeto ilergete del Tossal de les Tenalles, aunque no pueda asegurarse completamente su función. La distribución de estos objetos por el momento se circunscribe al norte del río Ebro (fig. 9). Sería un tipo antiguo que, no obstante, perduraría bastante tiempo, y que tendría afinidades centroeuropeas, como el ejemplar de Sopron. Las prácticas de sacrificio seguidas en esa estación húngara, un importante yacimiento vinculado a la denominada "Vía del ámbar" (Jerem, 1991: 379), tendrían correlación con numerosos ejemplos de caballos sacrificados -hasta 27 en el yacimiento de Le Brustolade-Altino- en las tumbas paleovénetas de la fase tardía de la cultura Este (450350 a.C.) (Riedel, 1984: 228), pero la bibliografía que hemos podido consultar nada nos dice sobre el sistema cierre seguido en la argolla del único ejemplar de Altino que conservaba un elemento metálico, y que se dataría en el siglo IV a.C. (Chieco Bianchi, Tombolani, 1988: 54 y fig. 63; Jerem, 1998: 329; Quesada, 2003: 14). Las relaciones e influencias entre el norte del Ebro y el mundo transpirenaico no constituyen una novedad y han sido bien demostrada para explicar el armamento de los iberos septentrionales, sin que ahora tengamos que extendernos en ello. 


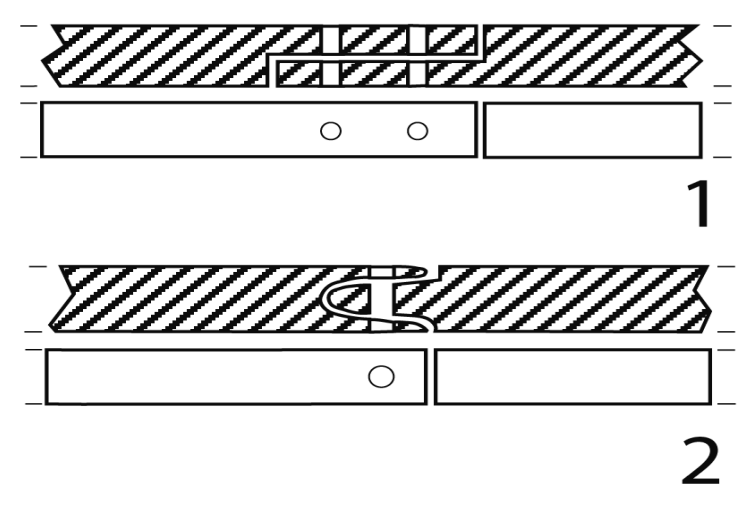

Fig. 8. Esquema de las dos tipologías en el cierre de aro para ronzal caballar.

\section{Tipo 2}

Consta de extremos diferenciados, uno de ellos remata en un pivote taladrado por un único agujero que encaja en la mortaja del otro extremo, igualmente con ojal (ejemplo en fig. 10, definición detallada en Mesado, 2003: 180, figs. 3-5 y 8). Por ahora estaría representado por siete ejemplares publicados, todos en el entorno levantino, cinco ya recogidos por Norberto Mesado: La Regenta y Torre d'Onda (ambos en Burriana, Castellón) -aunque debe reconocerse que el segundo muy afectado por la corrosión, por lo que no queda claro el sistema de cierre seguido-, El Solaig (Betxí, Castellón), Puntal dels Llops (Olocau, Valencia) y La Serreta (Alcoy, Alicante); las cronologías de esos ejemplares se situarían entre finales del siglo III y el siglo I a.C. (Mesado, 2003: 185). Los dos restantes pertenecen a la necrópolis de El Cigarralero (Mula, Murcia), uno de ellos apareció en la Tumba principesca n. 200, lo que lo convierte en el más antiguo del grupo, en concreto de la primera mitad del siglo IV a. C. (Lucas, 2004: 104, fig. 3), el otro apareció en el espacio 1-2 del santuario, pero no se conserva más que una descripción de Emeterio Cuadrado: "un trozo de torque semicircular de cobre macizo, pero con un extremo hueco y un agujero para el pasador" (Cuadrado, 1950: 36; Lucas, 2004: 104); la descripción puede ser suficiente para incluirlo en este grupo. El tipo 2 muestra una distribución homogénea en el Levante peninsular, en fechas que pertenecen a la cultura ibérica entre los siglos IV a I a.C. (fig. 9).

\section{LA CONTRIBUCIÓN DE LOS EJEMPLOS ICONOGRÁFICOS}

Obsérvese que las argollas detectadas son siempre circulares o casi, debido a deformaciones, con unos diámetros menores entre 6-8 cm (Lucas, 2004: 104) y mayores de 11,5 en el caso de Sopron (Jerem, 1998: 326). Resulta tentador deducir un diámetro mayor a medida que se seleccionaban los équidos y aumentaban estos en tamaño. Norberto Mesado señaló una forma diferente de argolla, en media luna, si bien mediante un ejemplo iconográfico en la excepcional representación de dos fragmentos de un mismo vaso pintado de El Solaig (Betxí) (Mesado, 2003: 182, fig. 6), pero el dibujo en cuestión platea muchas dudas, pues esos caballos también lucen una especie de muserolas o cabezadas, como ya observó Ma Rosario Lucas (Lucas 2004: 105). Coincidimos con esta autora en el sentido que parecen dudosos tanto ese como otros ejemplos de argollas señalados por Mesado, en concreto para Los Villares (Hoya Gonzalo, Albacete) y La Alcudia (Elche), puesto que podrían ser representaciones esquemáticas de frenos de 


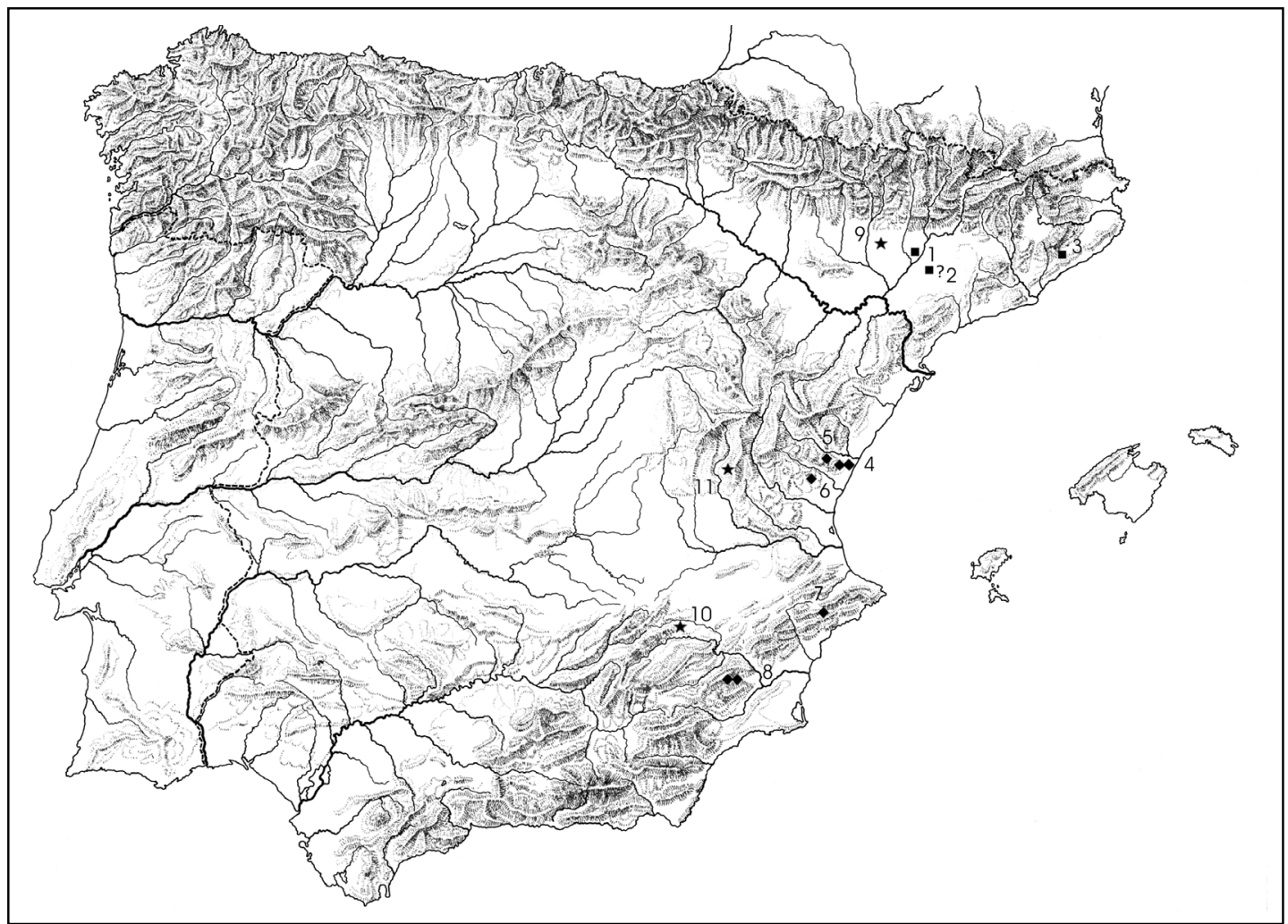

Fig. 9. Distribución de aros y ronzales conocidos en la Península Ibérica. Cuadrados: aros del tipo 1; rombos: aros del tipo 2; estrellas: representaciones iconográficas de ronzales. Yacimientos: 1. La Pedrera (Térmens, Lleida); 2. Tossal de les Tenalles (Sidamon, Lleida); 3. Turó del Vent (Llinars del Vallès, Barcelona); 4. La Regenta y Torre de l'Onda (Burriana, Castellón); 5. El Solaig (Betxí, Castellón); 6. Puntal dels Llops (Olocau, Valencia), 7. La Serreta (Alcoy, Alicante); 8. El Cigarralejo (Mula, Murcia); 9. La Vispesa (Tamarite de Litera, Huesca); 10. Elche de la Sierra (Albacete); 11. Villar del Humo (Boniches, Cuenca).

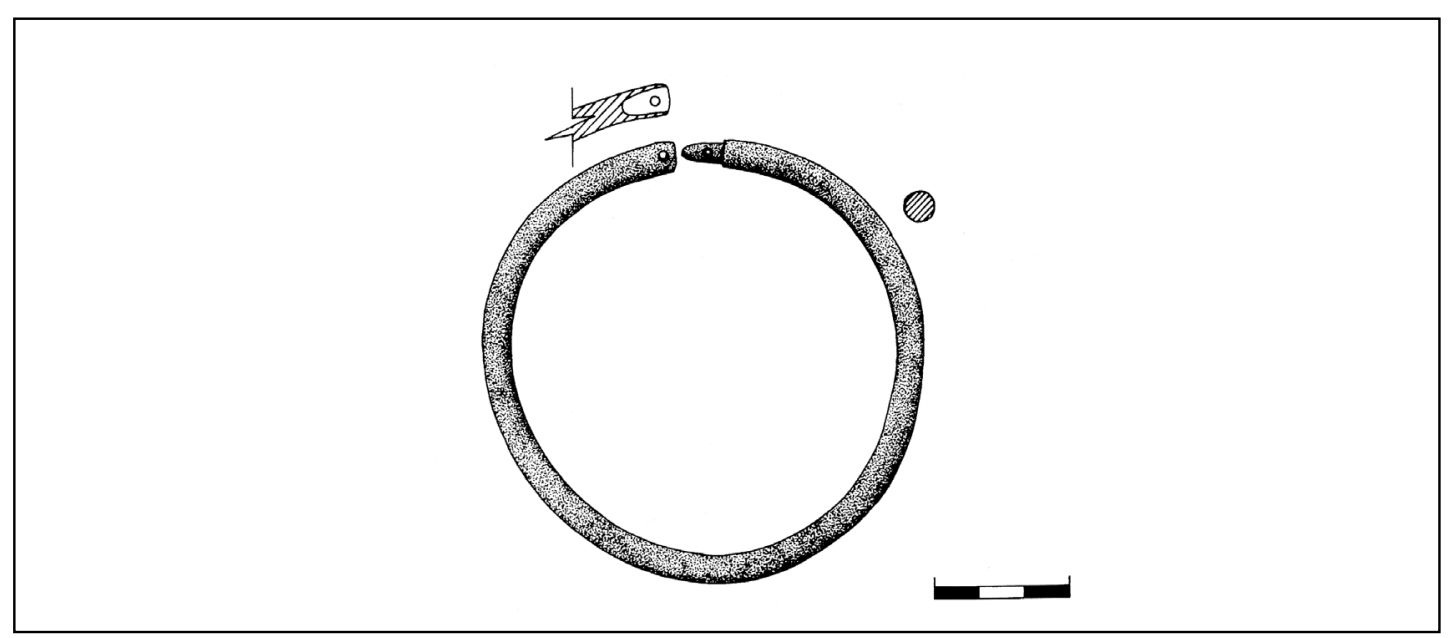

Fig. 10. Ejemplo de aro de ronzal del tipo 2. La Serreta (Alcoy, Alicante), según Mesado 2003: fig. 4, dibujo de Emili Contell. 
camas convencionales. En otro orden de cosas, son precisamente los ejemplos iconográficos válidos los que muestran los ronzales en toda su dimensión, como puede apreciarse en los casos en piedra de La Vispesa (Tamarite de Litera, Huesca) (fig. 7), cerámicos (Elche de la Sierra, Albacete) (Eiroa, 1986: fig. 2) (fig. 11) o en pintura rupestre en el abrigo del Villar del Humo (Boniches, Cuenca) (Lucas, 2004: 102, fig. 1). Es cierto que en éste último no se reproduce la argolla, pero su condición de ejemplo peninsular más antiguo, debe tenerse en cuenta para explicar su esquematismo, que solo permite comprender un ronzal que tira del belfo superior deformándolo, mejor que un narigón que tirase de los ollares, pues en la primera solución, por pura anatomía equina, justificaría la intencionada trompa que el anónimo pintor quiso indicar conscientemente y que observó agudamente $\mathrm{M}^{\mathrm{a}} \mathrm{R}$. Lucas (Lucas, 2004: 101-102).

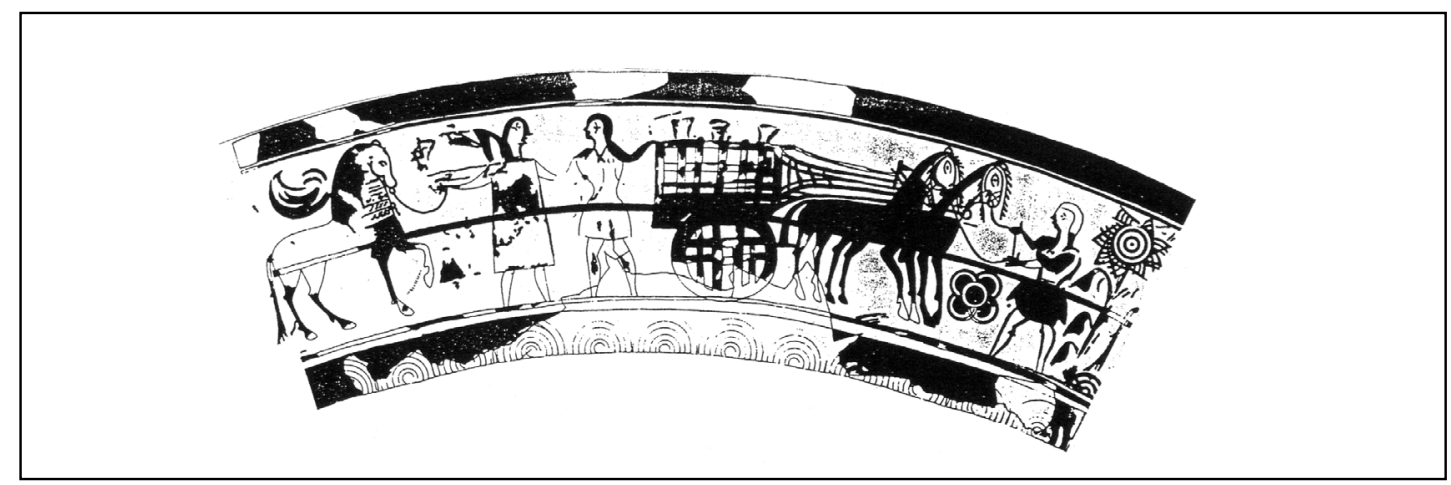

Fig. 11. Pegaso tirado por un ronzal. Decoración cerámica de Elche de la Sierra (Albacete), según J. J. Eiroa (1986: 77).

\section{EL EMPLEO DEL RONZAL CABALLAR DESDE UNA PERSPECTIVA HISTÓRICA}

Queda pendiente para el futuro desarrollar una explicación de como surgieron dos tradiciones diferentes en le cierre de los aros. Debe tenerse presente que, en cualquier caso, los más antiguos precedentes de argollas y ronzales no habrían sido ni mediterráneos ni continentales, y se remontarían a los primeros carros ligeros de dos ruedas del Asia Anterior, que se datarían a comienzos del tercer cuarto del segundo milenio a.C. En esos ejemplos, siempre iconográficos, los caballos estaban guiados mediante riendas finalizadas en aros ubicados en la parte superior del extremo de la boca, como puede observase en alguna representación en sello cilindro procedente de las colonia paleoasiria en Capadocia de Kültepe (Littauer, Crouwel, 1979: 68-71, figs. 28-29; Pare, 1992: 12, fig. 13) (fig. 12). Fernando Quesada ha sugerido que eran narigones dada la evidente posición que ocupan (nota como editor en Lucas, 2004: 107), no obstante, sugerimos que pueden alojarse en la boca y aparentar narigones por el hecho que el conductor tira de ellos hacia arriba, dada la simplificación de la escena. En cualquier caso, de confirmarse que eran narigones, habrían sido una experiencia poco repetida, pues en las iconografías posteriores las riendas parten justo del extremo de la boca (más lógicas si los aros metálicos se alojaban en los belfos), por ejemplo en algunas representaciones micénicas (Pare, 1992: fig. 25.1-2) (fig. 13) o incluso en el antiguo grabado escandinavo de Kivik (Skåne, Suecia) reproducidos por Crouwel (Pare, 1992: 14, fig. 18) (fig. 14), que pasa por ser una de las más antiguas representaciones europeas de un carro de dos ruedas, hacia 1300 a.C. Posteriormente, en iconografías ya del primer milenio a.C., los caballos, ahora sin carros, aparecen dominados por argollas que se alojan claramente en el belfo inferior, solución mecánicamente más lógica, bien para tirar de ellos manualmente (el ejemplo más claro en la pintura cerámica de Elche de la Sierra), bien para atarlos a postes y columnas (casos de relieve de La Vispesa o de la crátera etrusca mencionada). 


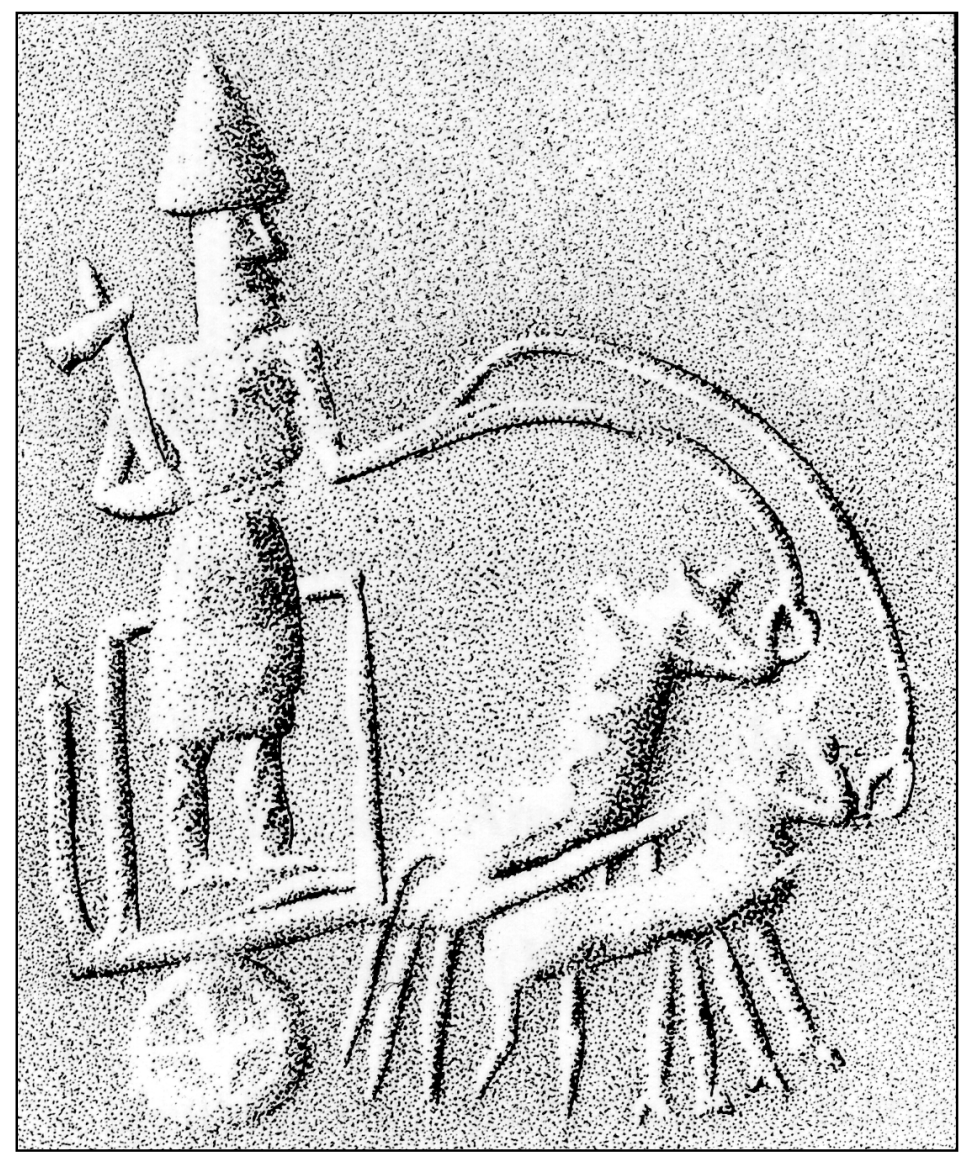

Fig. 12. Impresión de sello procedente de Asia Menor y guardado en el Metropolitan Museum de Nueva York, según Littauer y Crouwel, 1979 (tomado de Pare, 1992: 12).

Para explicar la adopción de las argollas de ronzal caballar en regiones tan distantes, desde la cuenca del Danubio y la región véneta al Valle del Ebro y el Levante peninsulares, debe tenerse presente que pudieron intervenir muchos elementos más allá de la simple imitación o el comercio. Recientemente, diversos autores han puesto de relieve el papel del caballo en los intercambios aristocráticos protohistóricos, en un plano en el que también tomarían parte las armas, las mujeres en matrimonio exogámico o los objetos suntuarios (SánchezMoreno, 2005: 238-239; Gabaldón, 2005: 268). Unas pautas que manifiestan las aristocracias emergentes europeas de la Edad del Hierro y aún antes, y que bien les pudo llevar a poner en circulación no sólo caballos, sino también elementos del control a ellos asociados a distancias considerables.

En el caso específico de la zona ilergete, las aristocracias emergentes parecen poseer complejos y singulares ritos relacionados con el mundo del caballo ya en fechas tempranas, tanto en necrópolis, caso de La Pedrera, como en poblados contemporáneos, según indican los fetos de caballo bajo vivienda en Els Vilars (Arbeca) (Gómez, 2003). Esas pautas van más allá de las concepciones que acompañan las deposiciones y se plasman en el prestigio del muy antiguo campo frisio que rodea el citado yacimiento de Els Vilars (GIP, 2003). Cuando, más tarde, la sociedad aristocrática ilergete entró en una vía estatal, el contingente de caballería siguió siendo una porción muy destacada del total del ejército, como resaltan las fuentes lite- 

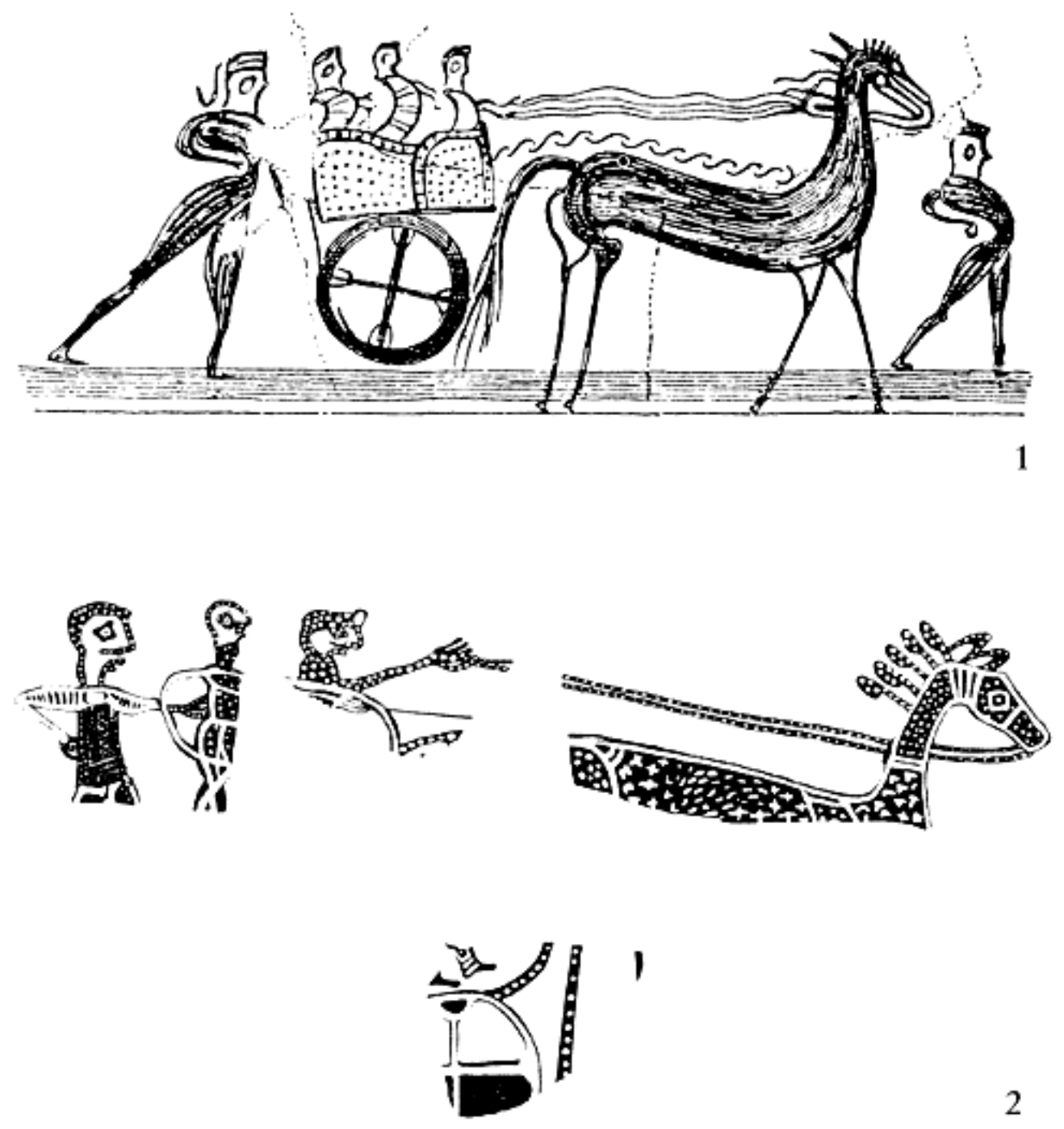

Fig. 13. Representaciones en cerámicas micénicas de caballos gobernados desde la boca: 1. Kition (Chipre); 2. Tirinto, según Pare, 1992: 21).

rarias antiguas (Quesada, 1997: 190-192), con independencia de la discusión sobre la utilidad práctica de esos escuadrones. Desde una la perspectiva histórica se entiende mejor el regalo de 300 caballos, capturados en Baecula, que Escipión libró a Indíbil (Liv. 27, 19, 1) como la continuación de una herramienta diplomática de primer orden. También ayuda a entender que se mantuviese viva en la iconografía del monumento, de regusto indigenizante, de La Vispesa, aunque ya estuviese en contacto con la escritura y con el comienzo de una nueva época. 


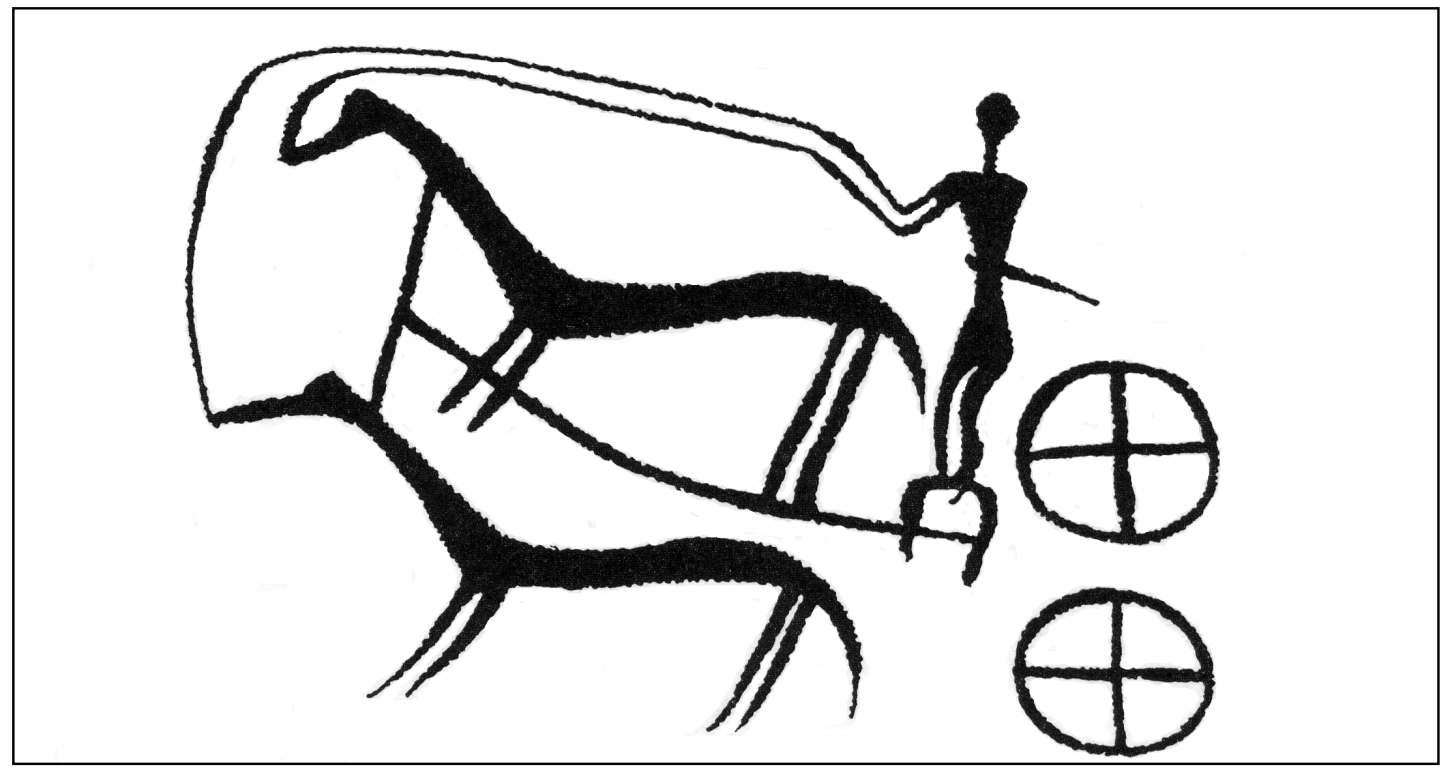

Fig. 14. Representación grabada de carro y caballos gobernados por la boca en Kivik (Skåne, Suecia), según Crouwel 1981 (tomado de Pare, 1992: 14).

\section{BIBLIOGRAFÍA}

Beltrán, A. (1970): «La inscripción ibérica de Binéfar en el Museo de Huesca», XI Congreso Nacional de Arqueología (Mérida 1968), Zaragoza: 518-522.

CuAdrado, E. (1959): Excavaciones en el Santuario Ibérico del Cigarralejo (Mula, Murcia), Informes y Memorias, 21, Madrid.

Chieco Bianchi, A. M.; Tombolani, M. (1988): I Paleoveneti, Giunta Regionale del Veneto.

EIROA, J. J. (1986): «El kalathos de Elche de La Sierra (Albacete)», Anales de Prehistoria y Arqueología, 2: 73-86.

GABALDÓN M. M. (2005): «Ponis, santuarios y guerreros: la dimensión ritual del caballo en el mundo galo», Gladius, XXV: 265-282.

GARCÉs, I. (2002): «Fre de cavall», en J. L. Ribes (ed.), Sala d'Arqueologia de l'IEI. Catàleg, Lleida: 200-201. IEI.

GARCÉS, I.: (en prensa) «Nuevas interpretaciones sobre el monumento ibérico de La Vispesa (Tamarite de Litera, Huesca)», Actas del XXVI Congreso Nacional de Arqueología (Zaragoza, 18-21 de abril de 2001), Caesaraugusta, Zaragoza.

Garcés, I.; Marí, L.; Pérez Conill, J.; PuChe, J. M. (1993): «Ocupacions del bronze recent i dels camps d'urnes tardans al Tossal de les Tenalles de Sidamon», Revista d'Arqueologia de Ponent, 3: 249-285.

GIP = Grup d'Investigació Prehistòrica (2003): «Caballos y hierro. El campo frisio y la fortaleza de "Els Vilars d'Arbeca" (Lleida, España), siglos VIII-IV a.n.e.», en N. Alonso, E. Junyent, A. Lafuente y J. B. López (coords.), Chevaux-de-frise i fortificació en la primera edat del ferro europea, Lleida: 233-274, Universitat de Lleida. 
GómeZ, X. (2003): «Fetos de équido en Els Vilars (Arbeca, Lleida). Un nuevo tipo de deposición animal en hábitat durante la Primera Edad del Hierro en Cataluña», en F. Quesada y M. Zamora (eds.), El caballo en la Antigua Iberia, Real Academia de la Historia, Madrid: 209-217.

Jerem, E. (1991): «L'abitato di Sopron-Krautacker», I Celti, Milano: 379.

JeREM, E. (1998): «Iron Age horse burial at Sopron-Krautacker (NW Hungary). Aspects of trade and religion», en P. Anreiter, L. Bartosiewicz, E. Jerem y W. Meid (eds.), Man and the Animal Worl. Studies in Archaeozoology, Archaeology, Anthropology and Palaeolinguistics in memoriam Sándor Bökönyi, Budapest: 319-334.

LitTAuer, M.A.; Crouwel, J. (1979): Wheeled vehicles and ridden animals in the Ancient Near East, Leiden.

LÓPEZ, A.; Rovira, J.; SANMARTí, E. (1982): Excavaciones en el poblado layetano del Turó del Vent. Llinars del Vallès. Campañas de 1980 y 1981, Diputació Provincial. Barcelona.

LuCAS, R. (2004): «Narigón y ronzal versus bocado de caballo: el arrastre de los équidos», Gladius, XXIV: 99-108, Barcelona.

Marco, F.; Baldellou, V. (1976): «El monumento ibérico de Binéfar (Huesca)», Pyrenae, 12: 91-115.

MARTELLI, M. (ed.) (1987): La ceramica degli Etruschi, Novara.

MAYA, J. L. (1986): «Incineració i ritual funerari a les valls del Segre i del Cinca», Cota Zero, 2: 39-47.

Mesado, N. (2003): «El caballo ibérico de La Regenta (Burriana, Castellón)», en F. Quesada y M. Zamora (eds.), El caballo en la Antigua Iberia, Real Academia de la Historia. Madrid, 179-186.

PARE, C. F. E. (1992): Wagons and Wagon-Graves of the Early Iron Age in Central Europa, Oxford, Madrid: 179-186.

Plens, M. (1986): La necròpolis de La Pedrera (Vallfogona de Balaguer-Térmens), tesis de licenciatura inédita, Estudi General, Lleida.

Plens, M. (2002): «Braçalet», en J. L. Ribes (ed.), Sala d'Arqueologia de l'IEI. Catàleg, IEI. Lleida: 179.

QuesADA, F. (1997): «¿Jinetes o caballeros? En torno al empleo del caballo en la Edad del Hierro peninsular», La Guerra en la Antigüedad. Una aproximación al origen de los ejércitos en Hispania, Ministerio de Defensa, Madrid: 185-194.

QuesADA, F. (2003): «El caballo en la Antigua Iberia», en F. Quesada, y M. Zamora (eds.), El caballo en la Antigua Iberia, Real Academia de la Historia, Madrid: 9-19.

QUESADA, F. (2005): «El gobierno del caballo montado en la Antigüiedad clásica con especial referencia al caso de Iberia. Bocados, espuelas y la cuestión de la silla de montar, estribos y herraduras», Gladius, XXV: 97-150.

RAFEL, N. (2002): «La necròpoli de La Pedrera (Vallfogona-Térmens), en J. L. Ribes (ed.), Sala d'Arqueologia de l'IEI. Catàleg, IEI, Lleida: 255-256.

RIEDEL, A. (1984): «The Paleovenetian Horse of Le Brustolade (Altino)», Studi Etruschi, 50: 227-256.

RIPOLL, E. (1959): «El poblado y la necrópolis ilergetas de 'La Pedrera' (Vallfogona de Balaguer, Lérida)», Ampurias, XXI: 275-279.

RodRíGUEZ RAMOS, J. (1997): «Primeras observaciones para una datación paleográfica de la escritura ibérica», Archivo Español de Arqueología, 70: 13-30.

SÁnCHEZ-Moreno, E. (2005): «Caballo y sociedad en la Hispania céltica: del poder aristocrático a la comunidad política», Gladius, XXV: 237-264.

SARRIón, I. (2003): «El caballo de la Regenta (Burriana). Estado de conservación y restauración», en F. Quesada y M. Zamora (eds.), El caballo en la Antigua Iberia, Real Academia de la Historia, Madrid: 187-190. 
SchÜle, W. (1969): Die Meseta-Kulturen der Iberischen Halbinsel, Deutsches Archäelogisches Institut, Madrid.

Untermann, J. (1990): Monumenta Linguarum Hispanicarum, III. Die iberischen Inschriften aus Spanien, Wiesbaden = MLH, III.

VV.AA. (1998): Los iberos, príncipes de Occidente, Fundación "La Caixa", Barcelona.

Recibido: 31/05/2007

Aceptado: 29/06/2007 